\title{
Progress in High Entropy Alloys
}

\author{
MICHAEL C. GAO ${ }^{1,2}$ \\ 1.-National Energy Technology Laboratory/AECOM, 1450 Queen Ave. SW, Albany, OR 97321- \\ 2198, USA. 2.—e-mail: michael.gao@netl.doe.gov
}

As advanced alloys with wide arrays of promising applications, high-entropy alloys (HEAs) have attracted rising interest from both academia and industry. Consequently, the TMS Alloy Phases Committee has sponsored and co-sponsored symposia on HEAs at Materials Science \& Technology 2012 and the TMS Annual Meeting \& Exhibition in 2013, 2014, and 2015. The symposia were well attended, and featured papers have been published in JOM $^{1-3}$ and Metallurgical \& Materials Transaction A. ${ }^{4,5}$ This current JOM topic "Progress in High Entropy Alloys" gives the readers a timely update on several important issues including physical metallurgy, mechanical properties, processing, oxidation, irradiation, and theoretical modeling. For comprehensive reviews and updates on other topics on HEAs please refer to Refs. 6 and 7 .

Yeh $^{8}$ provided two definitions for HEAs. One is based on chemical composition, and HEAs are defined to preferentially contain at least five principal elements, each with an atomic percentage between $5 \%$ and $35 \%$. The other is based on configurational entropy, and HEAs are defined as alloys having configurational entropies at a random state $\geq 1.5 \mathrm{R}$ ( $\mathrm{R}$ is the ideal gas constant), no matter whether they are single phase or multi-phase at room temperature. To date HEAs in the face-centered cubic (fcc) structure are exclusively based on the composition of $\mathrm{CoCrFeMnNi}$ discovered by Cantor et $\mathrm{al}^{9}{ }^{9}$ and its sub-systems summarized by $\mathrm{Wu}$ et al. ${ }^{10}$ In fact, these CoCrFeMnNi-based HEAs are the focus of the majority of the papers in this topic.

Twelve of the papers focus on experimental efforts on microstructure/processing/properties relationships, while the remaing four papers tackle atomic pressure and the phase formation rules using theoretical modeling tools. Yeh overviews the thermodynamics, kinetics and four core effects of HEAs

Michael C. Gao is the guest editor for the Alloy Phases Committee, a joint committee of the TMS Functional Materials Division (FMD) and the TMS Structural Metals Division (SMD); and coordinator of the topic Progress in High-Entropy Alloys in this issue. that are the keys to understanding the physical metallurgy. In particular, he emphasizes the severe lattice distortion effect. Gludovatz et al. reviews recent research on the processing, microstructure and mechanical properties of single fcc $\mathrm{CoCr}$ $\mathrm{FeMnNi}$ and emphasizes fracture toughness at subzero temperature. Assisted by CALPHAD modeling, Daoud et al. were able to obtain a microstructure consisting of a $\mathrm{L}_{2}$ ordered $\gamma^{\prime}$ phase embedded in a fcc solid solution $\gamma$ matrix together with needle-like B2 precipitates in $\mathrm{Al}_{10} \mathrm{Co}_{25} \mathrm{Cr}_{8} \mathrm{Fe}_{15} \mathrm{Ni}_{36} \mathrm{Ti}_{6}$. They found that the tensile strength at 600,700 and $800^{\circ} \mathrm{C}$ are very high, greater than commercial Alloy $800 \mathrm{H}$ and Inconel 617.

Jablonski et al. showed an example of the fabrication of two single-phase fcc $\mathrm{CoCrFeNi}$ and $\mathrm{CoCr}$ FeNiMn HEAs in large scale ingots by vacuum induction melting. They emphasized the importance of melting, homogenization and thermo-mechanical processing. Seifi investigated the fracture toughness and fatigue crack growth behavior of as-cast $\mathrm{Al}_{0.2} \mathrm{CrFeNiTi}_{0.2}$ and $\mathrm{AlCrFeNi}_{2} \mathrm{Cu}$; both consist of fcc and body-centered cubic (bcc) phases. Their fracture toughness is significantly less than $\mathrm{CoCr}$ FeMnNi. Mridha et al. studied the nano-mechanical behavior of $\mathrm{CoCrFeMnNi}$ in the as-cast, rolled, annealed, and thin-film forms using nano-indentation and concluded low stacking fault energy for the alloy. Park et al. studied the microstructure and mechanical properties of $\mathrm{Co}_{21} \mathrm{Cr}_{22} \mathrm{Cu}_{22} \mathrm{Fe}_{21} \mathrm{Ni}_{14}$ after high pressure torsion (HPT) and subsequent annealing processes and analyzed the hardening mechanisms during HPT. Using in-situ high-pressure energy-dispersive x-ray diffraction with synchrotron radiation at $0-24 \mathrm{GPa}$ pressure, $\mathrm{Li}$ et al. determined the pressure-volume equation of states of $\mathrm{AlCoCrCuFeNi}$ and found that the fcc + bcc composite structure remained stable. The temperature effect on serrated flow in $\mathrm{Al}_{0.5} \mathrm{CoCrCuFeNi}$ at 673-873 K was studied by Chen et al. who observed two opposite directions of serrations types. Diao et al. presents a short overview on the local structures of HEAs on atomic scales. 
The oxidation of eight HEAs based on $\mathrm{CoCr}$ FeMnNi, stainless steels $304 \mathrm{H}$ and Ni-based superalloy 230 at 650 and $750^{\circ} \mathrm{C}$ were studied by Holcomb et al. who concluded that maintaining high $\mathrm{Cr}$ contents while keeping $\mathrm{Mn}$ contents low is important for high-temperature applications. Xia et al. studied the irradiation behavior of $\mathrm{Al}_{x} \mathrm{CoCr}$ FeNi $(x=0.1,0.75$, and 1.5) under $3 \mathrm{MeV}$ Au-ions irradiation and found that the irradiation-induced volume swellings are significantly lower than conventional nuclear materials under similar irradiation dosages. Using first-principles calculations, Egami et al. calculated lattice distortion and atomic stresses, and concluded that strong atomic-level pressures are present in HEAs due not only to the differences in the intrinsic atomic sizes but due to charge transfer among the elements reflecting the differences in electronegativity. The presence of atomic stresses in HEAs position them as attractive candidates as nuclear materials.

Troparevsky et al. presented first-principles calculations of the electronic structure of the disordered solid solution phase based on both KorringaKohn-Rostoker Coherent-Potential-Approximation and conventional supercell models of example fcc and bcc systems. They further proposed a model to screen single-phase solid solution compositions based on the enthalpy data of binary compounds. Based on their Monte Carlo simulations, Liu et al. predicted the configurational entropy of $\mathrm{CoCrFeNi}$ is $1.329 \mathrm{R}$ at $1373 \mathrm{~K}$ and they further claimed that it required atomic size difference $\delta<0.05$ and enthalpy of mixing $(\Delta \mathrm{H})$ to be $-10 \mathrm{~kJ} / \mathrm{mol}<\Delta \mathrm{H}$ for $\mathrm{CoCrFeNi}$ to be single solid solution phase. Using first-principles calculations to study the phase stability in the $\mathrm{Al}_{x} \mathrm{CoCrFeNi}$ as a function of $\mathrm{Al}$ contents, King et al. predicted that fcc phase is stable for $0 \leq x \leq 0.75$, and the partially ordered bcc structure forms with $x>0.75$, agreeing with experimental results.

The following paper being published under the topic of "Progress in High-Entropy Alloys" provide excellent details and research on the subject. To download any of the papers, follow the URL http:// www.link.springer.com/journal/11837/67/10/page/ 1 to the table of contents page for the October 2015 issue (vol. 67, no. 10):

- "Physical Metallurgy of High-Entropy Alloys" Jien-Wei Yeh.

- "Processing, Microstructure, and Mechanical Properties of the $\mathrm{CrMnFeCoNi}$ High-Entropy Alloy" Bernd Gludovatz, Easo P. George, and Robert O. Ritchie.

- "High Temperature Tensile Strength of $\mathrm{Al}_{10}$ $\mathrm{Co}_{25} \mathrm{Cr}_{8} \mathrm{Fe}_{15} \mathrm{Ni}_{36} \mathrm{Ti}_{6}$ Compositionally Complex Alloy (High-Entropy Alloy)" H. M. Daoud, A. M. Manzoni, N. Wanderka and U. Glatzel.

- "Manufacturing of High Entropy Alloys" Paul Jablonksi, Joseph Licavoli, Michael C. Gao, and Jeffery Hawk.
- "Fracture Toughness and Fatigue Crack Growth Behavior of As-Cast High Entropy Alloys" Mohsen Seifi, Dongyue Li, Zhang Yong, Peter Liaw, and John J. Lewandowski.

- "Nanomechanical Behavior of CoCrFeMnNi High-Entropy Alloy" Sanghita Mridha, Santanu Das, Samir Aouadi, Sundeep Mukherjee, and Rajiv S. Mishra.

- "Microstructure and Mechanical Properties of $\mathrm{Co}_{21} \mathrm{Cr}_{22} \mathrm{Cu}_{22} \mathrm{Fe}_{21} \mathrm{Ni}_{14}$ Processed by High Pressure Torsion and Annealing" Nokeun Park, Xiang Li, and Nobuhiro Tsuji.

- "Equation of State of an AlCoCrCuFeNi HighEntropy Alloy" Gong Li, Daihong Xia, Pengfei Yu, Lijun Zhang, Peter K. Liaw, Yanchun Li, and Riping Liu.

- "Effects of Temperature on Serrated Flow of High-Entropy Alloy" Shuying Chen, Xie Xie, Bilin Chen, Junwei Qiao, Yong Zhang, Yang Ren, Karin A. Dahmen, and Peter K. Liaw.

- "Local Structures of High-Entropy Alloys (HEAs) on Atomic Scales: An Overview" Haoyan Diao, Louis J. Santodonato, Zhi Tang, Takeshi Egami, and Peter K. Liaw.

- "Oxidation of CoCrFeMnNi High Entropy Alloys" Gordon R. Holcomb, Joseph Tylczak, and Casey Carney.

- "Irradiation Resistance in $\mathrm{Al}_{x} \mathrm{CoCrFeNi}$ HighEntropy Alloys" S.Q. Xia, X. Yang, T.F. Yang, S. Liu, and Y. Zhang.

- "Local Electronic Effects and Irradiation Resistance in High-Entropy Alloys" T. Egami, M. Ojha, O. Khorgolkhuu, D. M. Nicholson, and G. M. Stocks.

- "Beyond Atomic Sizes and Hume-Rothery Rules: Understanding and Predicting HEAs" M. Claudia Troparevsky, James R. Morris, Markus Daene,Yang Wang, Andrew R. Lupini, and G. Malcolm Stocks.

- "Examination of Solid-Solution Phase Formation Rules for High Entropy Alloys from Atomistic Monte Carlo Simulations" Zhenyu Liu, Yinkai Lei, Corinne Gray, and Guofeng Wang.

- "Predicting the Crystal Structure and Phase Transitions in High-Entropy Alloys" D.M. King, S.C. Middleburgh, L. Edwards, G.R. Lumpkin, and M. Cortie.

\section{ACKNOWLEDGEMENTS}

The author acknowledges the Cross-Cutting Technologies Program of National Energy Technology Laboratory under the RES contract DE-FE0004000 .

\section{REFERENCES}

1. M.C. Gao, JOM 64, 828-829 (2012).

2. M.C. Gao, JOM 65, 1749-1750 (2013).

3. M.C. Gao, JOM 66, 1964-1965 (2014).

4. P.K. Liaw, G.Y. Wang, M.C. Gao, and S.N. Mathaudhu, Metall. Mater. Trans. A 45A, 179-179 (2014).

5. P.K. Liaw, G.Y. Wang, M.C. Gao, and S.N. Mathaudhu, Metall. Mater. Trans. A 46A, 1467-1467 (2015). 
6. Y. Zhang, T.T. Zuo, Z. Tang, M.C. Gao, K.A. Dahmen, P.K. Liaw, and Z.P. Lu, Prog. Mater. Sci. 61, 1-93 (2014).

7. M.C. Gao, J.W. Yeh, P.K. Liaw, and Y. Zhang, High-Entropy Alloys: Fundamentals and Applications (Cham, Switzerland: Springer, 2015).
8. J.-W. Yeh, JOM 65, 1759-1771 (2013).

9. B. Cantor, I.T.H. Chang, P. Knight, and A.J.B. Vincent, Mater. Sci. Eng. A 375-377, 213-218 (2004).

10. Z. Wu, H. Bei, F. Otto, G.M. Pharr, and E.P. George, Intermetallics 46, 131-140 (2014). 